\title{
Wave Climate Change Projection at the End of 21st Century
}

\section{Tomoya Shimura, Nobuhito Mori, Tracey Tom, Tomohiro Yasuda and Hajime Mase Disaster Prevention Research Institute, Kyoto University}

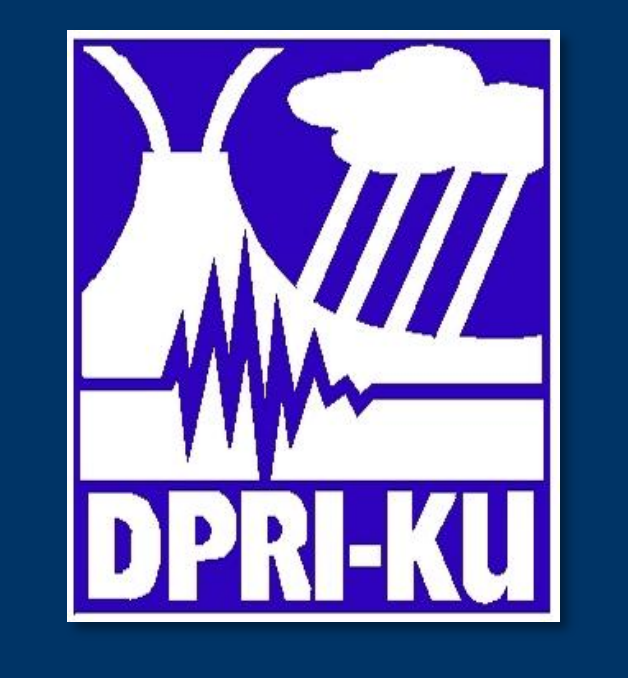

\section{Introduction}

The influences of global climate change due to green house effects will require impact assessment and adaptation strategies for future our society. The sea level rise is static side issue of climate change and is important for human activity near the coastal zone. On the other hand, wave and storm surge change are dynamic side of climate change and will be necessary taken into the consideration for coastal disaster prevention and reduction, If extreme weather events will become stronger than those in the present climate. This study estimates the future ocean wave climate in comparison with those in present climate based on the global atmospheric climate model and global wave model.

\section{Methods}

This research is conducted on the basis of global circulation model (GCM) developed by Meteorological Research Institute and Japan Meteorological Agency (JMA/MRI; Kakushin, 2008). The JMA-MRI GCM is the atmospheric T959L60 single model with SST from coarse grid coupled run of atmosphere and ocean coupled simulation, and is being computed for the three periods of 1979-2003 (Present) and 2075-2099 (Future) following A1B scenario. The global waves are simulated by the SWAN model, using sea surface wind $\left(U_{10}\right)$ of GCM. The simulated $U_{10}$ and wave height are analyzed to predict future wind and wave changes from the present to future.

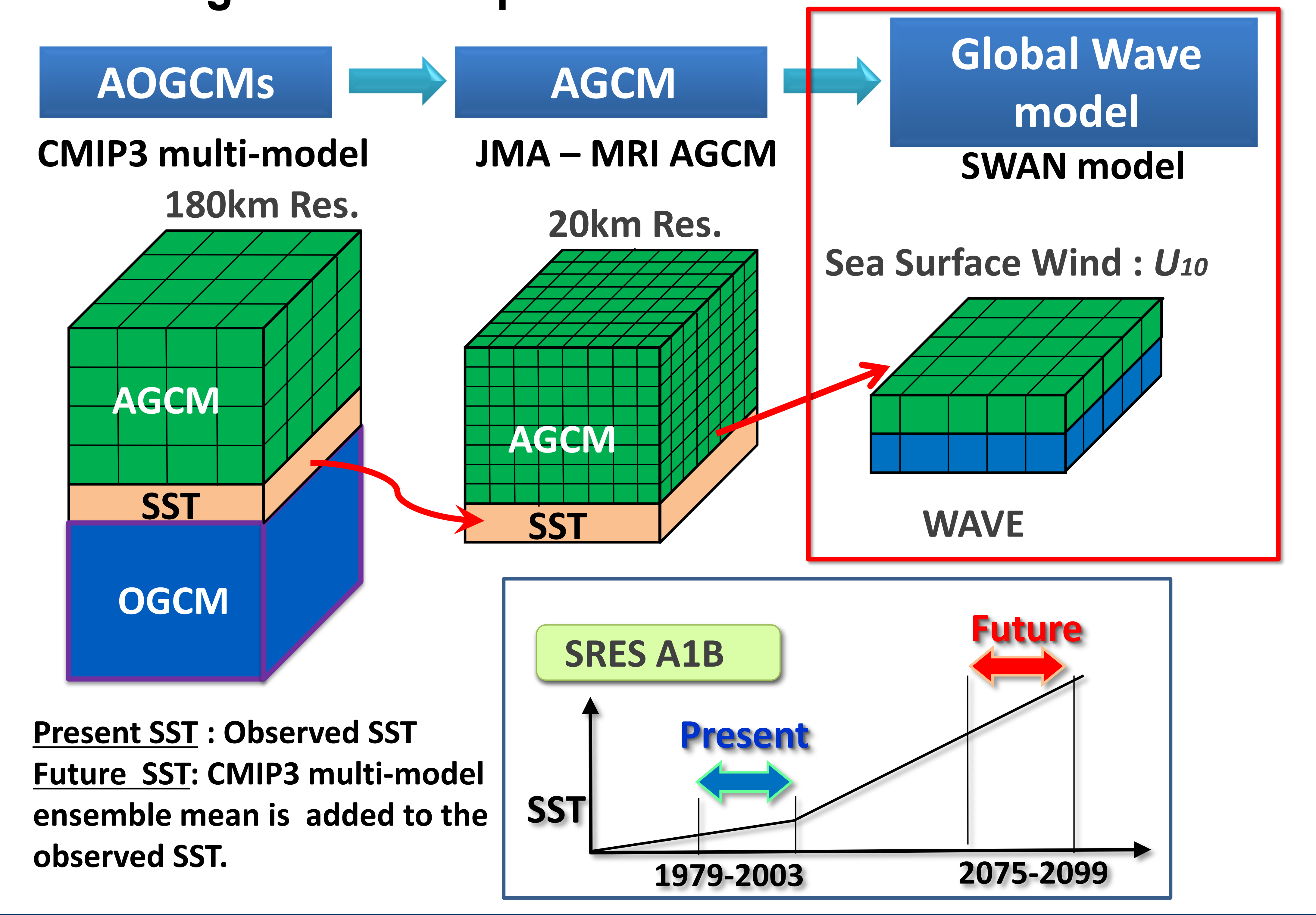

\section{Validity of Present Climate}

Significant wave height $(H s)$ and sea surface wind $\left(U_{10}\right)$ are simulated as the present climate value are validated against buoy measurements. In addition, $H_{s}$ and $U_{10}$ are compared with ECMWF ERA-40 data.

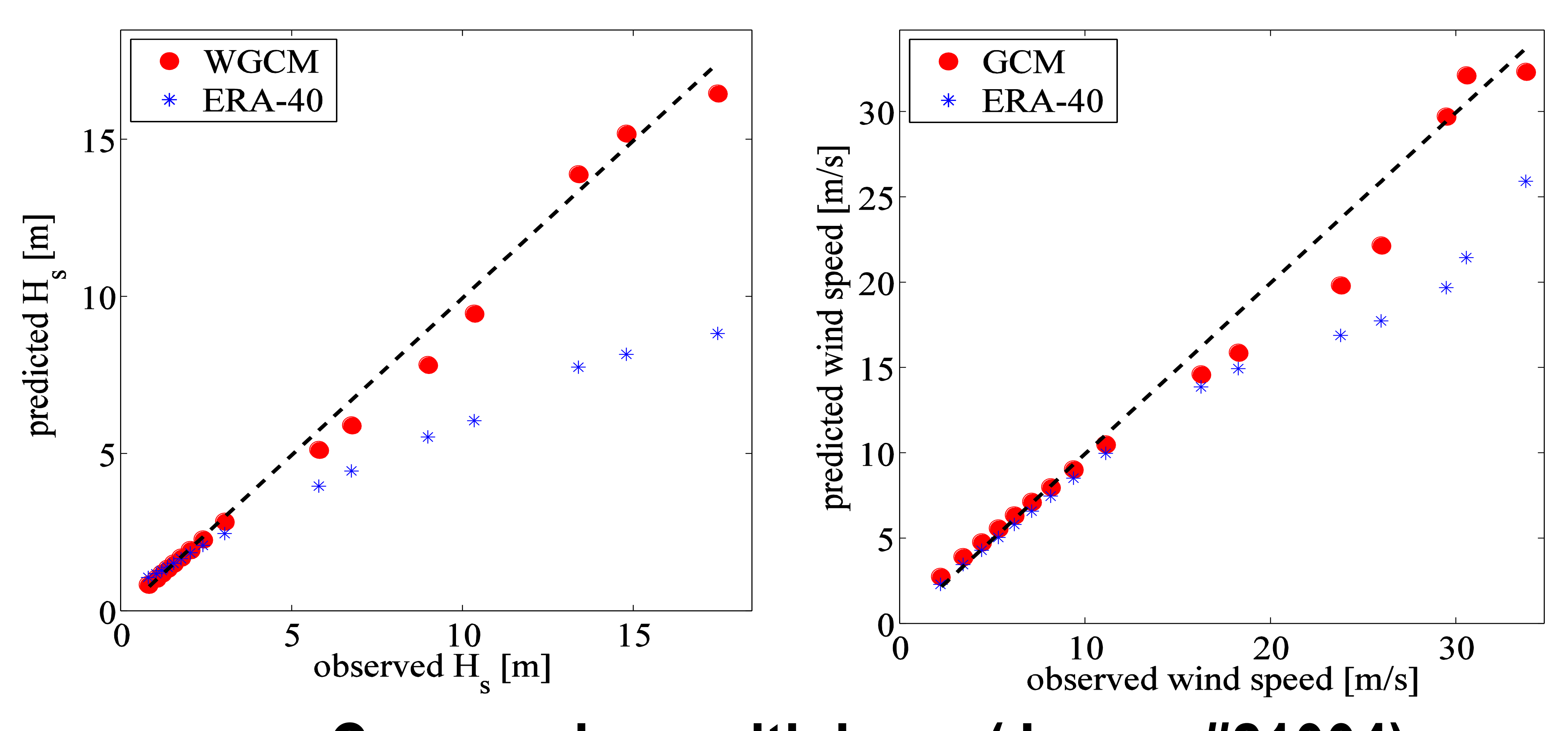

Comaparison with buoy (Japan, \#21004)

The validation of $H s$ and $U_{10}$ for other buoys and ERA-40 show that the simulated present climate value agrees with the observations well and the validity of extreme value is also especially highly accurate.

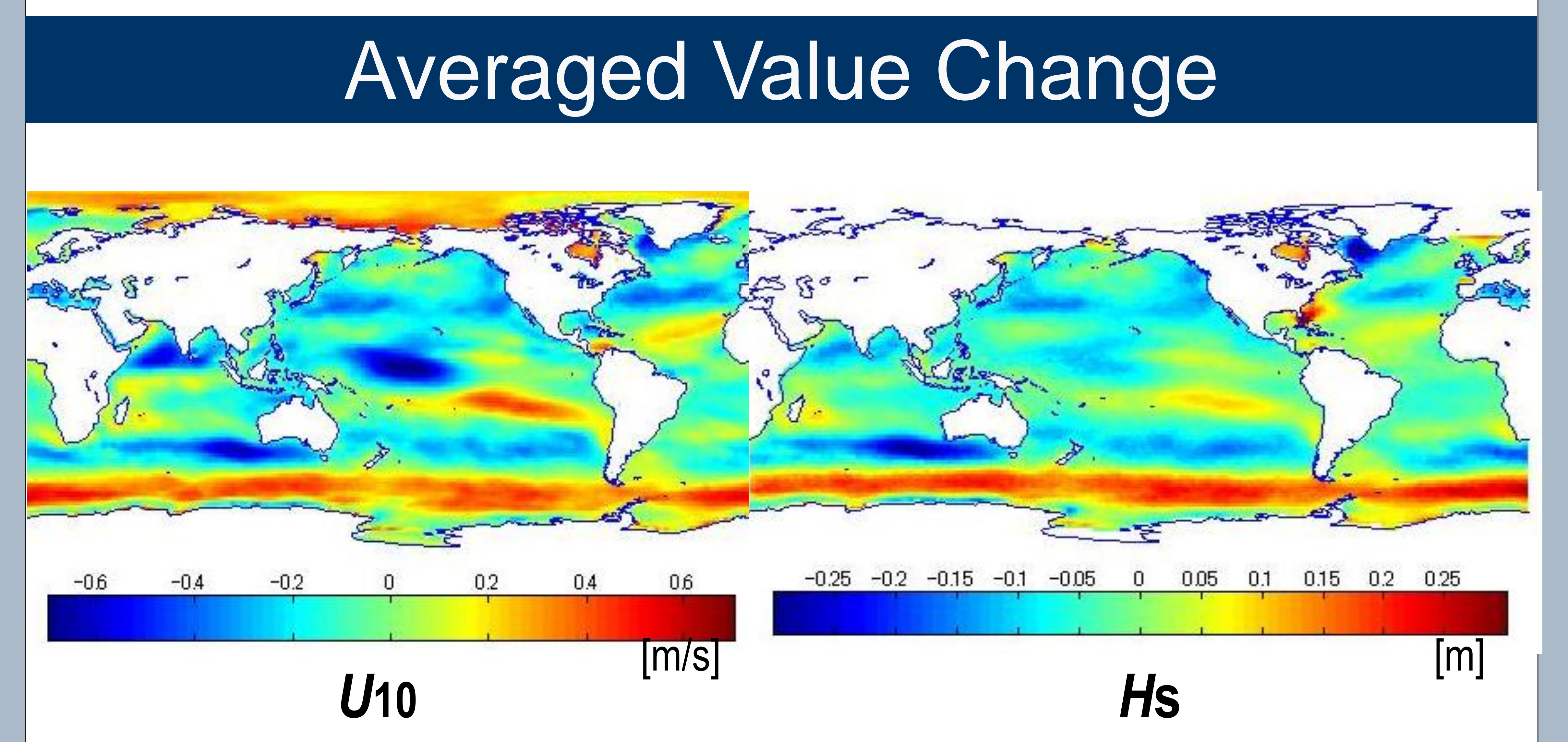

Annual averaged value : Future - Present

There are latitude and regional dependencies of averaged value of $U_{10}$ and $H s$ changes from present to future.

(1) The averaged $U_{10}$ and $H s$ at middle latitude westerlies and the Antarctic Ocean are increased by $4-7 \%$.

(2) The averaged values at horse latitude and the equator are decreased.

These spatial patterns of future change in averaged $U_{10}$ and $H s$ are quite similar. 


\section{Extreme Value Change}
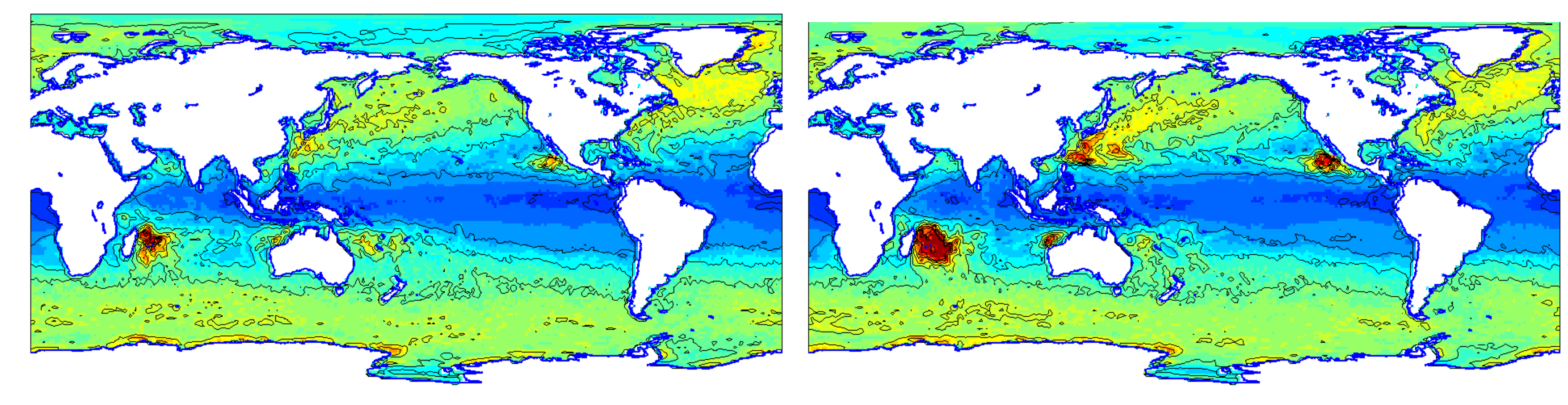

Present climate $[\mathrm{m} / \mathrm{s}]$

Future climate $[\mathrm{m} / \mathrm{s}]$

50 years return value of $U_{10}$

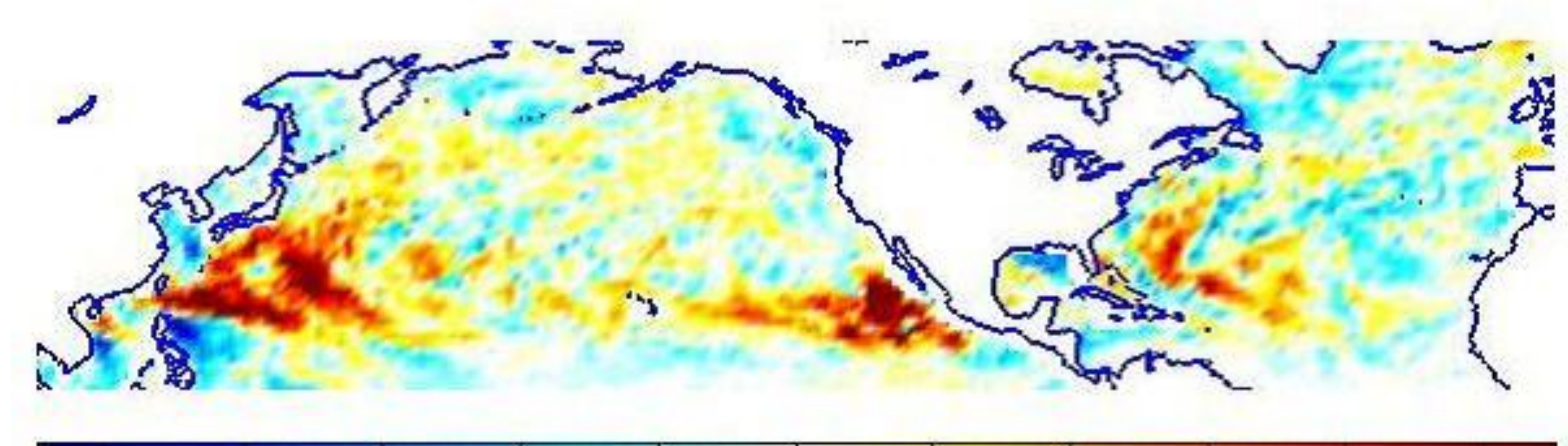

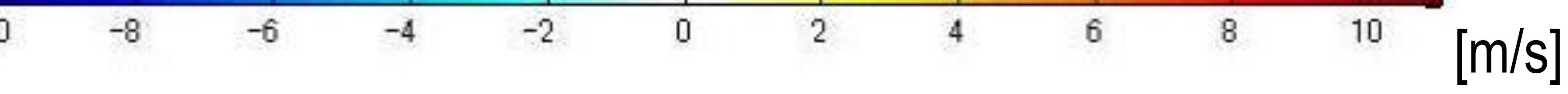

Future change : 50 years return value of $U_{10}$

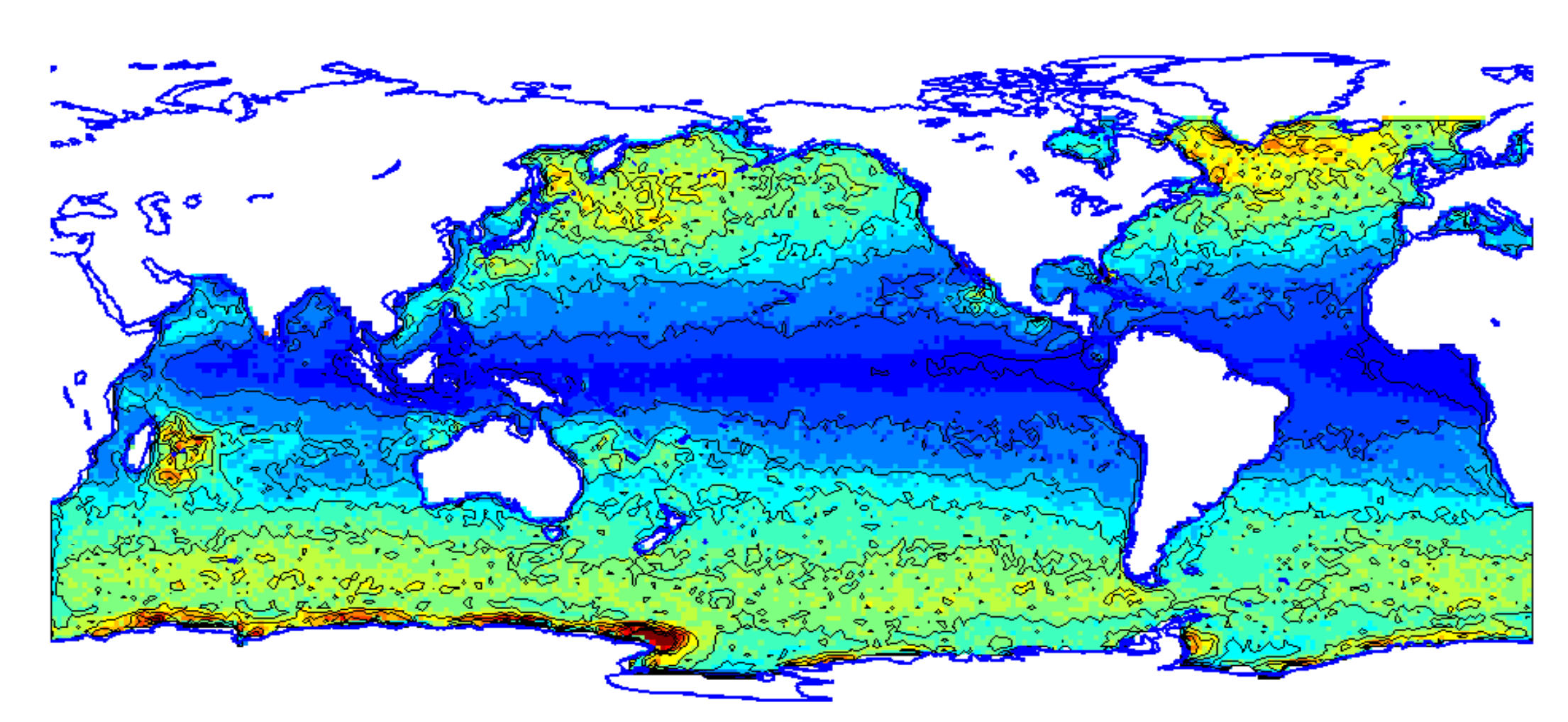

Present climate



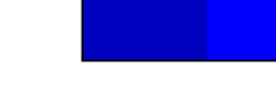

Future climate

[m]

50 years return value of $H s$

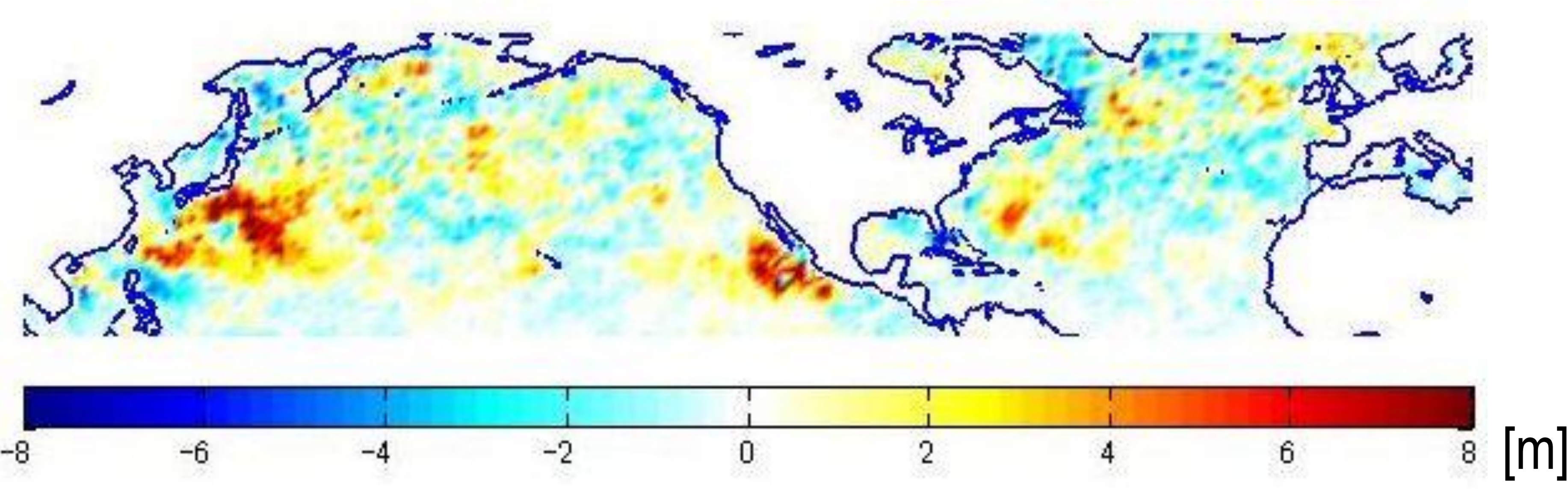

Future change : 50 years return value of $\mathrm{Hs}$

50 years return value as characteristic of extreme value are computed to fit the Generalized Pareto Distribution (GPD) by the peak over threshold data of $U_{10}$ and $H s$, respectively. There are some clear increases of 50 year return value in the storm tracks of tropical cyclones, such as the south sea of Japan, the western middle latitude of North Atlantic, the west sea of Mexico and the east sea of Madagascar. These results show that future tropical cyclones would become stronger and the range of their tracks would get larger.

\section{Regional Analysis near Japan}

Regional analysis for extreme values on Japan was conducted. The ensemble data in several areas are used for extreme analysis. 50 years return values were calculated in each area for winter (Nov.-April) and summer (May-Oct.).

As the results, 50 years return values in winter season are slightly changed from the present to future but number of extreme wave event is decreased significantly. On the other hand, the $\mathbf{5 0}$ years return values in summer season are increased, especially at the southeast sea of Japan. The extreme value analysis near Japan indicates the extreme $\mathrm{Hs}$ will be increased up to $60 \%$ and extreme $U_{10}$ will be increased up to $30 \%$.

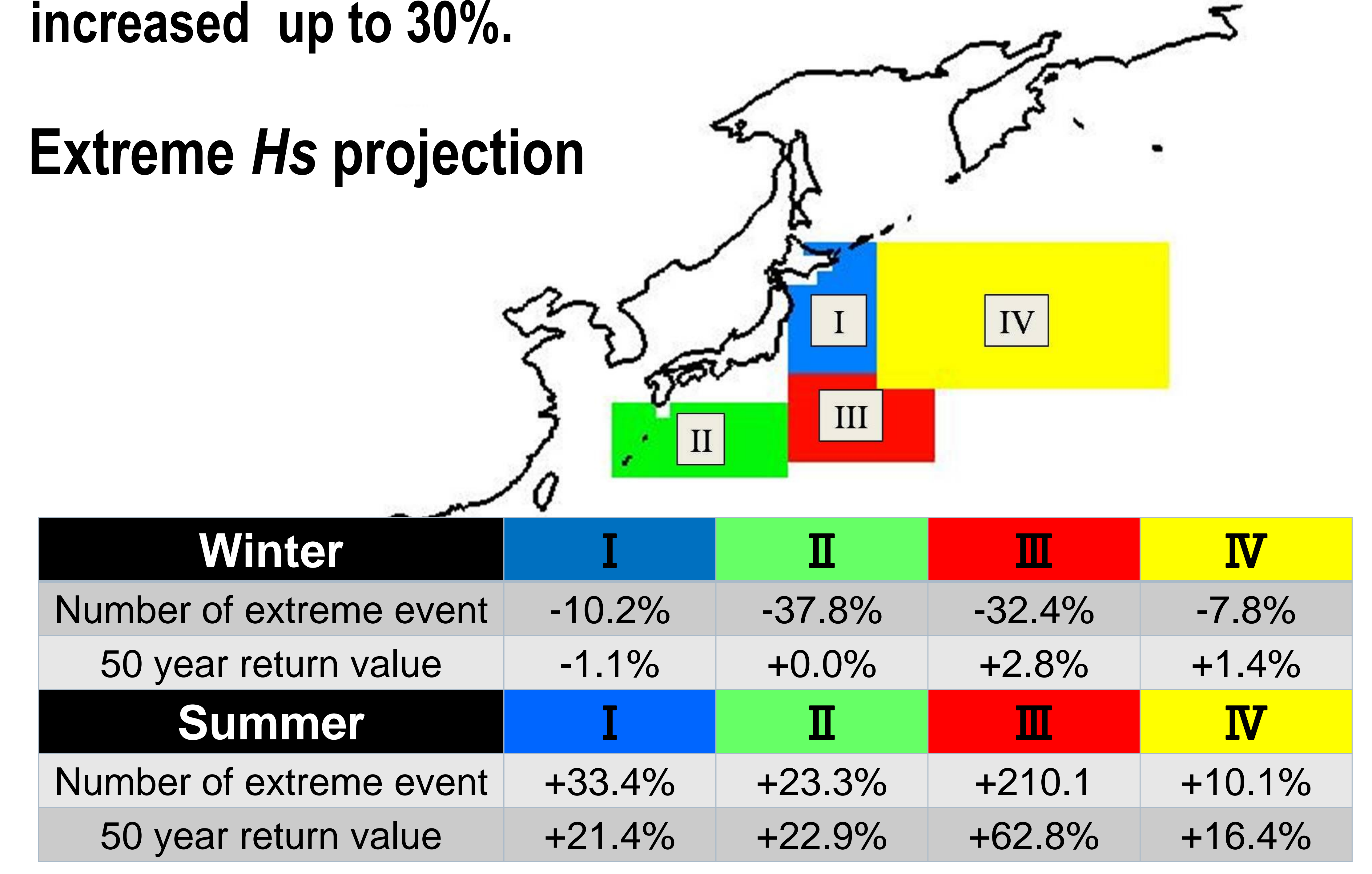

\section{Conclusions}

1. The present wave climate is verified with observations.

2. The future averaged $H s$ and $U_{10}$ will be changed depend on latitude.

3. The future extreme values of $H s$ and $U_{10}$ will be increased around tropical cyclone zones.

4. Future averaged and extreme change of $H s$ and $U_{10}$ have different spatial distributions.

\section{References}

Mori, N., T. Yasuda, H. Mase, T. Tom and Y. Oku (2010): Projection of extreme wave climate change under the global warming, Hydrological Research Letters, Vol. 4, pp. 15-19.

Kitoh, A., T. Ose, K. Kurihara, S. Kusunoki, M. Sugi and KAKUSHIN Team-3 Modeling Group (2009): Projection of changes in future weather extremes using super-highresolution global and regional atmospheric models in the kakushin program , Hydrological Research Letters, Vol. 3, pp.49-53.

\section{More information}

http://www.dpri.kyoto-u.ac.jp/ kaigan/

Email: mori@oceanwave.jp 